\title{
O bom jornalismo não morre, se reinventa
}

Géssica Gabrieli Valentini

\section{Géssica Gabrieli}

Valentini

Mestre e doutoranda em Jornalismo pelo Programa de Pós-graduação em Jornalismo da UFSC.

MIOLI, Teresa; NAFRÍA, Ismael (Editores). Jornalismo Inovador na América

Latina. E-book. Austin/USA: Centro Knight para o Jornalismo nas Américas, 2017.

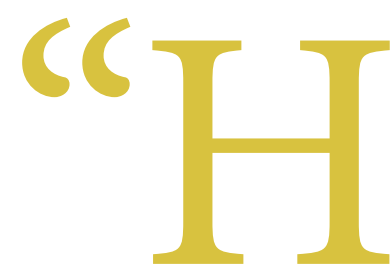

istória em
quadrinhos,
palavras-cruza-
das, realidade
virtual, jogos eletrônicos e até memes. À primeira vista, entretenimento. Porém, trata-se de jornalismo. E estas são algumas das apostas de novos e tradicionais meios de comunicação apresentadas no e-book "Jornalismo Inovador na América Latina”, que traz alternativas que 47 empresas de comunicação, de 11 países da América Latina e dos Estados Unidos, encontraram para driblar a crise na área. Conforme demonstram os projetos, ao jornalismo cabe a tarefa de continuar contando histórias, mas precisará encontrar novas formas de fazê-lo para conquistar um público que tem cada vez mais opções e distrações.

O livro reúne reportagens publicadas entre os meses de dezembro de 2016 e abril de 2017 no blog do Centro Knight para o Jornalismo nas Américas, da Universidade do Texas, e foi lançado no dia 23 de abril, durante o $10^{\circ}$ Colóquio Ibero-Americano de Jornalismo Digital. A coordenadora de conteúdo do Centro Knight, Teresa Mioli, e o jornalista Ismael Nafría foram co-editores do blog e editores do e-book. Além das reportagens, o livro ainda traz conselhos práticos sobre inovação jornalística digital.

A publicação dá uma dimensão abrangente de como as empresas de mídia estão se inventando ou reinventando, por meio de iniciativas que abrangem tanto o conteúdo e a forma, quanto a viabilidade econômica dos projetos. Por isso, o e-book torna-se relevante tanto para profissionais que atuam no mercado de trabalho, quanto para pesquisadores interessados em novas tecnologias.

Por ser um livro digital, consegue não apenas descrever as experiências, mas exemplificar através de hiperlinks inseridos no texto, de forma que a leitura não é linear, mas de acordo com o interesse de cada leitor.

As primeiras reportagens trazem experiências sobre uma das principais formas de consumo de conteúdo na internet: vídeos. O primeiro texto, escrito pelo jornalista César Lopez Linares, parte da experiência do site venezuelano Efecto Cocuyo para refletir sobre a decisão dos meios de comunicação na escolha de ferramentas de transmissão ao vivo, antes possível somente em canais de televisão. Apresenta as distinções entre plataformas, sobretudo o Periscope e o Facebook Live, com vantagens e desvantagens de cada um.

Já a segunda reportagem, assinada pelo mesmo jornalista, disserta sobre meios tradicionais, que diante da concorrência e também das novas tecnologias tentam se adaptar. A apuração de Linares mostra que, apesar do esforço, na América Latina os países ainda estão engatinhando quando o assunto 
são os vídeos em 360 graus e a realidade virtual. Conforme o autor, enquanto meios de comunicação como o New York Times ou a $B B C$ já apresentaram diversos trabalhos do chamado "jornalismo imersivo", as experiências em países como o Brasil e Argentina ainda são escassas, o que demonstra que ainda há muito para ser explorado. Além disso, esta reportagem revela uma característica em comum em praticamente todos os projetos de inovação: a multidisciplinariedade. Profissionais de diversas áreas juntos para pensar a melhor forma de comunicar.

Essa união de diferentes profissionais foi imprescindível para a experiência que foi tema da reportagem seguinte, sobre a Pictoline, uma empresa de desenho de informação. Intitulada "Veículo mexicano conquista a audiência ao explicar temas complexos em comunicação gráfica inteligente e divertida", a reportagem, também escrita por Linares, traz a história da empresa fundada por Eduardo Salles, um publicitário cujo objetivo era usar ilustrações, infografias e vinhetas publicadas nas redes sociais para informar. Para ele, se a sociedade está desinformada é porque a informação não é apresentada da forma correta. Para o criador da Pictoline, "se você é útil, então se torna necessário", e a experiência relatada na reportagem seguinte, "Jornalistas usam ferramentas digitais para criar mapas interativos de massacres na Colômbia", demonstra isso.

O site Yo Sobreviví traz relatos de sobreviventes e informações de todos os tipos e tornou-se uma base de dados, com uma apuração rigorosa, e até mesmo uma fonte de pesquisa para colombianos e órgãos do governo que desejam entender o conflito no país.

Enquanto isso, o texto "Como usar Facebook Live no jornalismo para maior interatividade com os usuários: lições da mídia em espanhol" retoma o tema dos vídeos ao vivo, mas agora traçando comparativos do alcance de transmissões simultâneas em relação a vídeos normais. Como traz a repor- tagem de César Lopez Linares, Brasil e México, por exemplo, são o segundo e terceiro colocados no consumo de vídeos no Facebook, atrás somente dos Estados Unidos, o que indica que há oportunidades nesta área. Após conversar com vários editores e com um representante do Facebook, o Centro Knight listou ainda dez casos de transmissões para refletir as essas experiências e as lições aprendidas.

Embora haja desafios, o bom jornalismo não morre. É o que acredita o personagem da reportagem: "O que fazer ao ser demitido de um jornal? Este repórter de Brasília criou uma startup e emprega mais de 20 jornalistas". Nela, a repórter Natalia Mazotte conta a história de Fernando Rodrigues, que após ser dispensado da Folha de S.Paulo, em 2014, lançou uma startup de cobertura política e mantém a empresa com assinaturas por uma newsletter corporativa sobre o tema.

Se a empresa de Fernando Rodrigues vai contra as estatísticas e segue crescendo com o jornalismo "tradicional", a reportagem " $\mathrm{Na}$ era dos tweets curtos, meios latino-americanos lançam projetos digitais inovadores de jornalismo long-form", também traz experiências semelhantes. Segundo o jornalista César López Linares, a Agência Pública, do Brasil, e a revista Gatopardo, do México, seguem apostando em grandes histórias, embora procurando explorar, além do texto, recursos multimídia.

Se até agora o livro abordou as experiências do ponto de vista da produção de conteúdo, nesta reportagem, intitulada "Mídias digitais venezuelanas lançam estratégia conjunta de publicidade para garantir rentabilidade", de César López Linares, expõe a estratégia de três sites da Venezuela, Runrun.es, Tal Cual e El Pitazo, que se uniram comercialmente para permitir a publicidade nos três sites, a um preço único, acreditando que assim ganham competitividade.

Em "O que você faria se fosse presidente? Jornalistas inovadores do 
Equador lançam um jogo interativo durante a cobertura eleitoral", César López Linares escreve sobre o Desafio Carondelet, um jogo online no qual os participantes podem tomar decisões sobre investimentos e gastos públicos, como se fossem o próprio presidente. $\mathrm{O}$ objetivo é atrair o público para essa área, que costuma não ser tão interessante.

Não só assuntos de política, mas diversos portais, como o Click Necesario, do México, e o Muy Lebre, da Argentina, também têm a proposta de apresentar informações com uma linguagem mais informal, com menos texto, mais imagens, vídeos curtos, listas, memes e manchetes cômicas. Esse foi o tema da reportagem "Com vídeos curtos, menos texto e muito humor, sites latino- americanos buscam fórmula para atrair os 'millennials"', escrita por César López Linares.

Não só de vídeos se fazem as inovações. Aproveitando a demanda de um mundo cada vez mais "parado" em congestionamentos ou filas de espera, a reportagem "Rádios tradicionais enfrentam nova concorrência na América Latina: os podcasts de veículos nativos digitais", também de César López Linares. Comenta os projetos da Radio Ambulante e também do portal de jornalismo político colombiano $\mathrm{La}$ Silla Vacía, que produzem podcasts diferenciados.

As reportagens seguintes versam sobre inovações na área de jornalismo investigativo. "Ojo Público, site peruano de jornalismo investigativo, experimenta formatos e narrativas digitais inovadores". De autoria de Paola Nalvarte, traz a história do portal do Peru que faz desenhos de investigações aplicando ferramentas digitais.

Já "Investigações sem fronteiras: jornalistas latino-americanos inovam em projetos transnacionais", de César López Linares, aborda o famoso caso Panama Papers, resultado da investigação que envolveu 370 jornalistas de 76 países, entre os quais 15 latino-americanos, que descobriram uma rede de evasão de impostos e criação de empresas em paraísos fiscais por parte de empresários e líderes mundiais. A descoberta levou a escândalos políticos e mostrou o impacto do jornalismo que ultrapassa fronteiras.

"Como o diário argentino $\mathrm{La} \mathrm{Na}$ ción se tornou a maior referência em jornalismo de dados da América Latina", de Natalia Mazotte, conta a história do repórter de política Diego Cabot, daquele jornal, que montou uma equipe que se dedica ao jornalismo de dados e coleciona prêmios nacionais e internacionais. Também traz a história do site de notícias brasileiro Nexo, fundado por uma cientista social, uma engenheira e um jornalista, que apostam no esforço conjunto para que a melhor forma seja encontrada, desde especiais interativos e até palavras-cruzadas para contar uma história.

A reportagem "A aposta no fact checking: jornalistas criam mais iniciativas para verificar o discurso público e revelar notícias falsas", produzido por Alessandra Monnerat, aborda outro fator essencial ao jornalismo: a checagem, seja do discurso público, notícias ou rumores. Traz diversos exemplos de organizações independentes de diferentes países que atualmente se dedicam a apuração, a fim de reduzir as chamadas fake news.

No final do livro, os editores reuniram diferentes jornalistas para apresentar sugestões práticas principalmente para quem atua na área. Fabiola Torres López, co-fundadora e editora do Ojo Público, do Peru, comenta como criar uma equipe de jornalismo de dados, enquanto o jornalista da Folha de S.Paulo André Monteiro dá conselhos para os meios de comunicação ampliarem seu público-alvo. O videojornalista Jorge Villalpando Castro dá dicas para criação de vídeos online e Pablo Fernández Delkader, do departamento de Inovação e Desenvolvimento de Produtos da PRISA Radio, comenta sobre a produção de podcasts. O e-book encerra com o texto de Jorge Luis Sierra, com recomendações sobre segurança digital e a proteção contra hackers. 
As mudanças tecnológicas e sociais, principalmente impulsionadas pela própria tecnologia, colocam o tema inovação como um dos mais importantes para todos os setores da sociedade, inclusive para a comunicação. Os consumidores de informação estão buscando novidades, como demonstram os exemplos, o que torna o livro interessante tanto para quem atua na área como para quem pesquisa o campo.

Por um lado, o livro não traz um aprofundamento teórico, mas mesmo para pesquisadores os cases registrados podem ajudar a traçar um panorama sobre o que está sendo produzido quando o assunto é inovação. Há no livro uma gama de casos que podem ser estudados, além de tendências para serem observadas. Tais referências revelam comportamentos tanto de usuários quanto de produtores de conteúdo, servindo de base tanto para quem pesquisa processos, quanto produtos e a sua recepção.

Além disso, a compilação também faz uma intercessão entre a teoria e a prática, preocupação constante de quem atua na academia, pesquisando comunicação, e também quem está no mercado de trabalho, mas ciente de que seu labor é - e deve ser - constantemente problematizado. Assim, embora o livro, como já exposto, seja uma coletânea de reportagens, merece atenção de todos os que têm interesse por inovações na área de comunicação.

Ademais, para jornalistas, talvez a principal constatação do e-book seja esta: o bom jornalismo não morre. Es- tamos o tempo todo falando de inovação, sim, mas a preocupação comum dos profissionais da comunicação é, antes de tudo, sobreviver diante das mudanças.

A rica exemplificação denota que o desafio não só é possível como é mais simples do que parece, ou seja, continuar fazendo o que sempre fizemos: jornalismo.

O processo não mudou: apurar bem e contar boas histórias, mas agregando justamente as potencialidades que as inovações tecnológicas permitem. Mais do que nunca, percebemos que não se trata de inventar algo novo, mas de uma reinvenção, de um estímulo à criatividade, a pensar além do conteúdo, embora este continue sendo essencial.

Os leitores, os espectadores não só continuam existindo, como estão consumindo cada vez mais conteúdo. Por isso, ao invés de ver como empecilho, somos motivados, através dos exemplos, a enxergar como um verdadeiro "mundo" de possibilidades, onde só é preciso aproveitar as oportunidades. Porque o bom jornalismo, este não morre, se reinventa.

Com versões em espanhol, inglês e português, o e-book pode ser baixado gratuitamente no site do Centro Knight.

Disponível em: https://knightcenter. utexas.edu/pt-br/ebook/jornalismoinovador-na- america-latinapt-br .

Versão em português: https://knightcenter.utexas.edu/books/PIPortugues.pdf 